\title{
KAJIAN WACANA IKLAN PADA PESAN SINGKAT (SMS)
}

\author{
Riani \\ Balai Bahasa Provinsi Daerah Istimewa Yogyakarta
}

\begin{abstract}
Abstrak
Iklan biasanya disampaikan kepada publik melalui media cetak, radio, dan televisi. Namun, iklan juga dapat disampaikan secara personal dengan melalui pesan singkat yang dikirimkan ke telepon gengam pembaca. Wacana iklan pada pesan singkat menarik untuk dikaji karena memiliki keunikan dibandingkan wacana iklan pada media lainnya. Oleh karena itu, kajian ini ditujukan untuk mendeskripsikan wacana iklan pada pesan singkat dari aspek struktur wacana, penggunaan bahasa, dan pragmatik. Objek pada kajian ini adalah iklan yang disampaikan melalui pesan singkat pada telepon genggam. Data diperoleh dengan cara mendokumentasikan iklan dari tahun 2014 sampai dengan Agustus 2015. Pendekatan penelitian ini adalah kualitatif deskriptif karena disesuikan dengan karakteristik data serta tujuan penelitian. Karakteristik data berupa kata-kata atau kalimat pada wacana. Hasil penelitian ini menunjukkan bahwa struktur wacana pada pesan singkat terdiri atas bagian pembuka, isi, dan penutup dengan variasi struktur bahwa tidak semua wacana memiliki bagian pembuka. Aspek penggunaan bahasa menunjukkan bahwa dalam wacana iklan terdapat kalimat majemuk dan tunggal disertai pelesapan, huruf kapital kerap digunakan untuk menekankan informasi yang penting, singkatan juga dipakai untuk meringkas isi. Aspek pragmatik pada wacana iklan menunjukkan bahwa tuturan direktif dan ekspresif dimanfaatkan pembuat iklan untuk memengaruhi pembaca iklan agar melakukan pembelian terhadap produk yang ditawarkan.
\end{abstract}

Kata kunci: wacana iklan, pesan singkat, struktur wacana, pemakaian bahasa, dan pragmatik.

\begin{abstract}
Adertising is usually delivered to the public through print, radio, and television medium. However, advertising can also be delivered in person through text messages sent to reader mobile phone. Advertising discourse on the short message is interesting to study because it is unique compared to advertising discourse in other media. Therefore, this study aimed to describe the advertising discourse in a short message from the aspect of discourse structure, use of language, and pragmatic. Object of the study is ads delivered through short messages on mobile phone. Data is obtained by documenting the ads received from 2014 to August 2015. This research approach is qualitative descriptive because it is in line with data characteristic and research aim.
\end{abstract}


Data characteristic is word and sentence in the discourse. The result indicates that the discourse structure on short message consists of opening part, content part, closing part and variation structure that not all discourse has opening part. Language use aspects shows that in advertising discourse there is single sentence and coumpound sentence accompanied deletion, capital letters are often used to emphasize important information, the abbreviation is also used to summarize the contents. Pragmatic aspects on advertising discourse denote that directive speech and expressive speech used to influence advertising reader to purchase the offered products.

Keywords: advertising discourse, short message, discourse structure, language use, and pragmatic.

\section{Pendahuluan}

Pemasaran merupakan salah satu upaya yang dilakukan produsen untuk memperkenalkan produk atau jasanya kepada masyarakat luas atau calon konsumennya. Dalam pemasaran produk atau jasa, iklan memiliki peranan penting karena iklan mengomunikasikan tidak hanya informasi produk tetapi juga apa kelebihan produk barang atau jasa sehingga menarik calon konsumen untuk membelinya. Untuk itu, bahasa dan unsur-unsur audio serta visual pendukung iklan dikemas dengan menarik.

Meskipun demikian, proporsi unsur bahasa dan unsur pendukung baik audio maupun visual pada suatu iklan tidaklah sama tergantung pada saluran sarana komunikasi yang digunakan, misalnya iklan pada media radio berbeda dengan iklan di koran. Iklan dengan menggunakan saluran komunikasi radio menitikberatkan pada kemasan bahasa yang disampaikan secara audio; sementara itu, iklan pada media koran mengedepankan tampilan visual berupa gambar dan bahasa tulisan yang dibatasi oleh ruang. Seperti halnya iklan pada koran, iklan yang disampaikan melalui pesan singkat (SMS) juga memiliki keterbatasan ruang sehingga kata-kata atau kalimat dikemas seefektif serta seefisien mungkin dengan menggunakan singkatan atau bentuk kalimat pendek.

Dari segi wacana dan pemakaian bahasa, iklan pada pesan singkat sangat menarik untuk dikaji karena berbeda dengan jenis iklan media lain, yaitu radio, televisi ataupun surat kabar. Untuk memperjelas deskripsi data iklan pada pesan singkat, berikut contohnya.

1. Kupu2 cantik trbg kelangit, hei km cantik,kok kece bingitz! Mau SMS Hitz bingitz plus hadiah pulsa 100rb tiap hr?2rb/30hr,385/sms otmt. Balas SMS ini ketik:OKE

Data ini terdiri atas empat kalimat. Dilihat dari struktur wacana, iklan ini diawali dengan kalimat pembuka, yaitu Kupu2 cantik trbg kelangit, hei km cantik, kok kece bingitz! Isi iklan berupa tawaran produk dinyatakan pada pertanyaan Mau SMS Hitz bingitz plus hadiah pulsa 100rb tiap hr? Penutup wacana berisi prosedur untuk mendapatkan produk yang dinyatakan dengan kalimat Balas SMS ini ketik:OKE. Penggunaan bahasa pada iklan ini terdiri atas banyak singkatan meliputi $\mathrm{km}$ (kamu), trbg (terbang), hr (hari), rb (ribu), dan otmt (otomatis). Penggunaan kata ulang kupu-kupu disingkat dengan menggunakan angka 2, yaitu kupu2. Penggunaan garis miring (/) difungsikan untuk menggantikan kata tiap atau per, misalnya $2 \mathrm{rb} / 30 \mathrm{hr}$ (2 ribu tiap 30 hari) atau penggunaan tanda baca garis miring (/) dapat dimaknai dengan kata untuk (2 ribu untuk 30 hari). Penggunaan kata bingitz merupakan plesetan dari kata banget. Penggunaan kata bingitz ini menunjukkan bahwa iklan singkat ini ditujukan untuk kalangan konsumen remaja yang menguasai bahasa gaul dengan ciri bahasa pelsetan dalam pengejaannya. 
Dari data itu dapat diketahui bahwa iklan pada pesan singkat memiliki keunikan baik dari segi struktur maupun bahasanya. Meskipun iklan ini terdiri dari beberapa kalimat, informasi yang disampaikan diupayakan semaksimal mungkin. Fungsi informasi pada pesan singkat dinyatakan dengan penggunaan singkatan. Untuk mencapai tujuan tersebut syarat kebakuan bahasa diabaikan dan daya pragmatik iklan ditonjolkan. Daya tarik iklan dikemas dengan menggunakan bahasa persuasif pada pernyataan Mau SMS Hitz bingitz plus hadiah pulsa 100rb tiap hr?2rb/30hr,385/sms otmt dan Balas SMS ini ketik:OKE. Isi pada iklan ini menawarkan produk layanan jasa SMS berisi hiburan (berita selebritis, lelucon, zodiak, dll.). Untuk mengetahui lebih lanjut seperti apa dan bagaimana wujud iklan pada pesan singkat, berikut beberapa permasalahan yang akan dikaji dalam makalah ini.

(1) Bagaimana struktur wacana iklan pada pesan singkat?

(2) Bagaimana penggunaan bahasa pada iklan pesan singkat?

(3) Bagaimana aspek pragmatik pada iklan pada pesan singkat?

Sesuai dengan permasalahan itu, tujuan yang hendak dicapai ialah sebagai berikut.

(1). Terdeskripsinya struktur wacana iklan pada pesan singkat.

(2) Terdeskripsinya bentuk bahasa yang digunakan dalam iklan pada pesan singkat.

(3) Terdeskripsinya aspek pragmatik iklan pada pesan singkat.

\section{Metode}

Penelitian ini menggunakan metode kualitatif dan deskriptif. Pendekatan kualitatif digunakan karena data yang dikaji bukan berupa angka-angka, tetapi berupa tuturan dalam wacana iklan pada pesan singkat. Objek penelitian ini adalah penggunaan bahasa dan aspek pragmatik dalam tuturan wacana iklan pada pesan singkat. Data penelitian ini berupa wacana iklan yang diterima pada pesan singkat (SMS). Pengumpulan dan analisis data ini melalui prosedur penelitian, yaitu penyediaan data, penganalisisan data yang telah disediakan, dan penyajian hasil analisis data (Sudaryanto, 2001:5). Penyediaan data dilakukan dengan cara mencatat pesan singkat (SMS) yang berisi iklan sejak bulan Januari 2014 sampai dengan Agustus 2015. Dalam penganalisisan data, data diklasifikasikan berdasarkan aspek-aspek kebahasaan dan jenis tuturan yang digunakan. Pada penyajian hasil analisis data digunakan metode deskripsi secara informal atau menggunakan kata-kata.

\section{Kerangka Teori}

Berdasarkan KBBI (2008:521), iklan berarti berita pesanan untuk mendorong, membujuk khalayak ramai agar tertarik pada barang dan jasa yang ditawarkan. Iklan juga dapat bermakna pemberitahuan kepada khalayak mengenai barang atau jasa yang dijual serta dipasang di dalam media massa (seperti surat kabar dan majalah) atau di tempat umum. Sementara itu, iklan dalam bahasa Inggris sepadan dengan kata advertising. Kata advertising, menurut Klepper (1986) dalam Mulyana (2005:63), berasal dari bahasa Latin ad-vere yang berarti 'menyampaikan pikiran dan gagasan kepada pihak lain'.

Sementara itu, Kasali (1992: 121) mendefinisikan iklan sebagai pesan yang berisi penawaran suatu produk kepada masyarakat melalui media. Senada dengan pernyataan Kasali, Swastha (1994: 252) menekankan bahwa tujuan utama iklan adalah bagaimana 
memberikan penawaran produk kepada calon konsumen. Dari penawaran ini diharapkan dapat memengaruhi pikiran serta mendorong konsumen untuk bertindak melakukan pembelian sehingga penjualan dapat terjadi segera atau di masa yang akan datang. Demikian halnya pada pesan singkat berisi penawaran hiburan atau unduhan lagu populer dapat dikatakan sebagai salah satu jenis iklan pada media telepon genggam.

Dilihat struktur pembentuk iklan, iklan pada pesan singkat merupakan sebuah wacana sekaligus sebagai tindak tutur. Kridalaksana (2001:231) mendefinisikan wacana sebagai satuan bahasa terlengkap, dalam hirarki gramatikal merupakan satuan gramatikal tertinggi atau terbesar.Wacana ini direalisasikan dalam bentuk karangan yang utuh, paragraf, kalimat, atau kata yang membawa amanat yang lengkap. Dilihat dari tujuannya, wacana diklasifikasikan menjadi wacana eksposisi, argumentasi, narasi, deskripsi, dan persuasi (Keraf, 1995:6).

Wacana persuasi merupakan suatu bentuk wacana yang berusaha memengaruhi orang lain atau pembaca untuk melakukan sesuatu sesuai dengan yang diperintahkan. Iklan termasuk wacana persuasi karena pesan yang disampaikan dan bertujuan untuk memengaruhi pikiran calon konsumen untuk melakukan apa yang dikehendaki pembuat pesan, yaitu membeli produk yang ditawarkan. Sebagai sebuah wacana, iklan memiliki struktur dan bagian-bagian padu yang terdiri atas pembuka, isi, dan penutup (Rani, 2000:56).

Iklan sebagai wacana persuasif memiliki pilihan kata dan tuturan yang khas. Kekahasan penggunaan bahasa iklan dicirikan dengan penggunaaan tuturan yang mencerminkan suatu tindakan pembuat tuturan untuk membuat orang lain (pembaca atau pendengar iklan) melakukan pembelian. Tindakan memengaruhi orang lain melalui tuturan dalam wacana iklan termasuk ke dalam kajian pragmatik. Pragmatik menurut Leech (1993:5-6) merupakan ilmu yang memelajari maksud ujaran, yaitu untuk apa ujaran itu dilakukan dan mengaitkan makna tuturan berdasarkan konteks yang meliputi kepada siapa, di mana, dan bagaimana tuturan tersebut disampaikan. Tuturan dalam iklan tentu saja dimaksudkan untuk dapat dipahami pembaca. Untuk itu penutur selalu berusaha agar tuturannya selalu relevan dengan konteks, jelas, dan mudah dipahami, padat dan ringkas, dan selalu pada persoalan sehingga tidak menghabiskan waktu pembaca (Wijana, 1996:45).

Menurut John R. Searle (1969: 23-24) terdapat tiga macam tindak tutur, yaitu tindak tutur lokusi (locutionary acts), tindak tutur ilokusi (illocutionary acts), dan tindak tutur perlokusi (perlocutionary acts). Tindak tutur lokusi adalah tindak tutur untuk menyatakan sesuatu. Tindak tutur ilokusi adalah tindak tutur yang berfungsi untuk mengatakan sesuatu dan dapat juga dipergunakan untuk melakukan sesuatu (Wijana, 2009: 22). Menurut Searle (1969) dalam Rahardi (2003: 72) tindak tutur ilokusi ini dapat digolongkan dalam aktivitas bertutur itu ke dalam lima macam bentuk tuturan yang masing-masing memiliki fungsi komunikatifnya. Kelima macam bentuk tuturan tersebut adalah asertif, direktif, deklarasi, komisif, dan ekspresif. Tindak tutur perlokusi adalah tindak tutur yang diutarakan oleh seseorang dan seringkali mempunyai daya pengaruh atau efek bagi yang mendengarkannya.

Wacana iklan dalam pesan singkat sebagai wacana persuasif menggunakan tindak tutur tertentu yang akan ditelaah lebih lanjut pada kajian ini. Selain pemanfaatan tindak tutur, aspek penggunaan bahasa berupa pilihan kata, singkatan, penulisan iklan juga 
memberikan ciri khas wacana iklan pada pesan singkat. Oleh karena itu, pada kajian ini dideskripsikan pemakaian kalimat, pilihan kata, penulisan huruf, dan penggunaan singkatan pada iklan dalam pesan singkat.

\section{Analisis/Pembahasan}

Iklan dalam pesan singkat memiliki keterbatasan dalam penyampaian pesannya. Pesan iklan yang disampaikan dibatasi oleh jumlah karakter karena keterbatasan media yang hanya dapat menampilkan kata-kata, kalimat, dan tanda baca. Untuk itu, kreativitas pembuat iklan sering kali dinyatakan dengan pemilihan kata-kata bahasa gaul, penulisan kata dengan huruf besar, tanda baca secara berlebihan, dll. Pada umumnya iklan dalam pesan singkat tidak memperhatikan kaidah penulisan ejaan. Meskipun demikian, iklan memiliki struktur yang terdiri atas bagian pembuka, isi, dan penutup. Pemanfaatan tuturan dilakukan secara maksimal untuk memengaruhi pembaca untuk membeli produk. Untuk mengetahuinya, berikut ini analisis struktur, penggunaan bahasa, dan tindak tutur dalam iklan pada pesan singkat.

\subsection{Struktur Wacana}

Struktur iklan dalam pesan singkat, seperti wacana yang lain, terdiri atas bagian awal, tengah, dan akhir. Uraian secara lebih terperinci dapat dilihat pada contoh dan pembahasan berikut ini.

\subsubsection{Bagian awal}

Untuk mengetahui apa saja yang terdapat pada bagian awal iklan dalam pesan singkat, dapat diperhatikan pada data berikut ini.

(1) SPESIAL UNTUK KAMU! ISI PULSA minimal Rp 25rb bisa raih hadiah MOBIL HONDA BRIO \&UANG RATUSAN JUTA! Jangan sampai hilang kesempatannya!

(2) Selamat! Anda masih punya kesempatan beli PAKET 500 hari ini. Pilih paket di ${ }^{\star} 100 * 999 \#$. Ayo beli paket MURAH Rp500!

(3) Kerjain temen yuk! Tlp mereka pake latar belakang music ROMANTIS. HOROR. MACET sampe LAPANGAN BOLA dll. tinggal pilih. Pasti seru! $\mathrm{Tlp}^{\star} 123^{\star} 252^{\star} 2 \#$ cuma $5 \mathrm{rb} / 14 \mathrm{hr}$

(4) Khusus utk anda! Isi pulsa s/d Rp15rb,dptkan Total Pulsa Rp17rb(2rb pulsa Tsel utk 3hr). Promo s/d 26Mei15. Cek bonus di *889\#. S\&K berlaku

(5) Valentine gini perlu dong Pulsa Jutaan \& PowerBank! Spesial buat kmu yg suka donlotklip romantic Korea Rp3300/7hr. Buruan hub ${ }^{\star} 123^{\star} 2200^{\star} 1 \#$ CS:817

Pada data (1) terdapat kata-kata SPESIAL UNTUK KAMU! yang mendahului katakata bagian inti iklan, yaitu ISI PULSA minimal Rp 25rb bisa raih hadiah MOBIL HONDA BRIO \&UANG RATUSAN JUTA! Pada data (2) ada kata Selamat! yang mendahului bagian inti yang berisi pernyataan Anda masih punya kesempatan beli PAKET 500 hari ini. Pilih paket di *100*999\#. Ayo beli paket MURAH Rp500! Pada data (3) bagian pembuka berisi pernyataan Kerjain temen yuk! Bagian ini mendahului isi iklan, yaitu TIp mereka pake latar belakang music ROMANTIS. HOROR. MACET sampe LAPANGAN BOLA dll. tinggal pilih. Pasti seru! TIp*123*252*2\# cuma 5rb/14hr. Pada data (4) 
bagian pembuka diwakili dengan pernyataan Khusus utk anda!. Bagian isi berisi pernyataan Isi pulsa s/d Rp15rb,dptkan Total Pulsa Rp17rb(2rb pulsa Tsel utk 3hr). Promo s/d 26Mei15. Cek bonus di *889\#. S\&K berlaku. Pada data (5) terdapat bagian pendahuluan yang dinyatakan dengan pernyataan Valentine gini perlu dong Pulsa Jutaan \& PowerBank!. Bagian isi iklan dinyatakan dengan kalimat Spesial buat kmu yg suka donlotklip romantic Korea Rp3300/7hr. Buruan hub *123*2200*1\# CS:817.

Dari beberapa contoh di atas terlihat bahwa kata-kata yang mengawali iklan pada pesan singkat difungsikan untuk menyapa pembaca dan mengkondisikan pembaca dengan isi iklan yang akan disampaikan. Cara menyapa pembaca iklan dilakukan dengan mengucapkan kata atau kalimat pembuka, misalnya SPESIAL UNTUK KAMU!, Selamat!, Khusus utk anda!, dIl. Sementara itu, pembuka wacana berisi pengkondisian pembaca iklan dikaitkan dengan konteks isi iklan, misalnya pada data (4) menggiring pembaca dengan kalimat pembuka yang berisi kondisi yang terjadi saat tersebut, yaitu hari Valentine 'Valentine gini perlu dong Pulsa Jutaan \& PowerBank!'. Dari beberapa contoh di atas menunjukkan bahwa iklan pada wacana pesan singkat memiliki struktur bagian pembuka. Namun, tidak semua iklan pada pesan singkat memiliki bagian awal atau pembukaan karena terdapat pula iklan pada pesan singakat yang langsung diawali dengan bagian inti atau isi iklan. Hal ini bisa dilihat pada uraian selanjutnya.

\subsubsection{Bagian Isi}

Bagian isi ialah bagian yang menjadi inti pembicaraan. Menurut Baryadi (2002:14), bagian ini berfungsi sebagai pemapar isi iklan. Bagian inti iklan baris ditempatkan sesudah bagian awal. Berikut ini contohnya.

(6) Gak usah nunggu sampe Lebaran utk jd jutawan! Buru update status gokilmu di Pop Call \& RAIH HADIAH THR RATUSAN JUTA RUPIAH! Hub ${ }^{*} 123 * 5500 * 9$ \#

(7) Uda siap menang hadiah total JUTAAN rupiah? Ayo nyanyi bareng Repvblik. Dan tunjukin kehebatan loe di XL Karaoke. Telp ${ }^{*} 123^{*} 89$ \# hny Rp 1500/7 hari.

(8) Liburan segera tiba! Lindungi diri \& keluarga dgn Mega-XL Proteksi Rp 3300/30hr. Ketik Nama(spasi)TgllahirDDMMYY(spasi)Nama Ibu Kandung kirim ke 4567. Info 817

Pada data (6) terdapat kalimat Gak usah nunggu sampe Lebaran utk jd jutawan!. Kalimat ini merupakan bagian awal wacana iklan. Bagian isi dinyatakan pada kalimat Buru update status gokilmu di Pop Call \& RAIH HADIAH THR RATUSAN JUTA RUPIAH!. Hal ini menunjukkan bahwa bagian awal iklan diawali dengan ajakan untuk tidak menunggu lama untuk dapat menjadi jutawan. Bagian inti iklan baris ini menginformasikan cara memperoleh hadiah atau menjadi jutawan dengan memasang status di Pop Call. Pop call adalah layanan gratis dari penyedia jasa Telkomsel, pelanggan Telkomsel dapat membuat status yang dapat muncul di layar telepon genggam penerima telepon saat pembuat status menelepon. Bagian inti diikuti bagian penutup, yaitu Hub*123*5500*9\# CS817GL040A1. Nomor ini menginformasikan bagaimana pembaca yang berminat dapat memeroleh informasi lebih lanjut serta langkah selanjutnya untuk mendapat status gokil dan hadiah THR (Tunjangan Hari 
Raya).

Pada data (7) terdapat bagian awal, yaitu Uda siap menang hadiah total JUTAAN rupiah? Bagian inti dinyatakan dengan pernyataan Ayo nyanyi bareng Repvblik. Dan tunjukin kehebatan loe di XL Karaoke. Bagian penutup berisi nomor kontak yang dapat dihubungi Telp *123*89\# hny Rp 1500/7 hari. Bagian awal memberitahu penerima pesan bahwa ada hadiah total jutaan yang kemudian diberitahu pada bagian isi bagaimana mendapat hadiah jutaan tersebut. Bagian isi menerangkan cara untuk mendapat hadiah jutaan, yaitu dengan mengikuti lomba karaoke lagu Repvblik di XL Karaoke. Untuk dapat mengikuti lomba tersebut peminat dapat menghubungi nomor kontak telepon $* 123 * 89 \#$.

data (8) bagian awal iklan adalah Liburan segera tiba! Sementara itu, bagian isi berisi pernyataan Lindungi diri \& keluarga dgn Mega-XL Proteksi Rp 3300/30hr. Bagian penutup berisi cara memeroleh jasa asuransi dengan melakukan prosedur yang tertera pada kalimat Ketik Nama(spasi)Tgllahir DDMMYY(spasi)Nama Ibu Kandung kirim ke 4567. Info 817.

Namun demikian, struktur iklan dalam pesan singkat tidak selalu memiliki bagian awal. Beberapa iklan langsung memuat bagian isi saja atau bagian isi dan penutup seperti pada contoh berikut ini.

9. TELKOMSEL Cukup dial ${ }^{\star} 108 \#$ dptkan paket hemat dan nikmati internet Wifi sd 100 Mbps di WifiCorner. Lokasi Wificorner di www, wificorner. Id info: (areacode) 147

10. HiburanAsik $\operatorname{Tlp}^{*} 123^{\star} 969^{*} 1 \#$ buat nemenin curhat si ganteng Aliando yg bingung pilih Nikita Willy atau Prilly! Cinta segitiga? $\mathrm{Rp} 3 \mathrm{rb} / 7 \mathrm{hr}$ Yg lain? ${ }^{\star} 123^{\star} 789 \#$

11. $181818 \mathrm{CEK}^{*} 123^{*} 93^{*} 9$ \# utk Aktifkan RBT ANTI JOMBLO BONUS NELPON 15 menit:"AK LAGI MOOD BUAT PACARAN AHHH..ATAU KM MAU JD PACAR AKU” Rp4rb/ bln

Pada data (9) struktur wacana iklan baris tidak memakai bagian awal, iklan itu langsung dimulai dengan bagian inti, yaitu Cukup dial *108\# dptkan paket hemat dan nikmati internet Wifi sd 100 Mbps di WifiCorner. Lokasi Wificorner di www, wificorner. Id info: (areacode) 147. Iklan ini menawarkan jaringan internet tanpa kabel di beberapa lokasi. Pembaca pesan yang berminat dapat menghubungi nomor *108\# dan informasi lebih lanjut mengenai jasa internet tanpa kable ini dapat menghubungi nomor (kode daerah setempat) kemunian menekan nomor 147.

Pada data (10) langsung mengemukakan isi iklan dengan memberikan informasi bagaimana mendapatkan berita artis Aliando, yaitu T/p *123*969*1\# buat nemenin curhat si ganteng Aliando yg bingung pilih Nikita Willy atau Prilly! Cinta segitiga?. Bagian penutup berisi informasi harga untuk mendapatkan berita artis tersebut. Selain itu, kalimat bentuk pertanyaan Yg lain? disampaikan dalam pesan tersebut untuk menawarkan pilihan berita artis lain yang dapat diperoleh dengan menghubungi nomor kontak *123*789\#.

Data (11) berisi inti iklan, yaitu CEK *123*93*9\# utk Aktifkan RBT ANTI JOMBLO 
BONUS NELPON 15 menit:"AK LAGI MOOD BUAT PACARAN AHHH..ATAU KM MAU JD PACAR AKU". Iklan ini menawarkan RBT ( Ring Back Tone) atau nada latar dering yang berupa lagu dengan judul AK LAGI MOOD BUAT PACARAN AHHH..ATAU KM MAU JD PACAR AKU dengan cara menghubungi nomor*123*93*9\#. Selain itu, dengan mengaktifkan nada dering ini konsumen dapat menikmati gratis untuk menelpon selama 15 menit. Struktur yang dicontohkan pada (9)-(11) merupakan struktur iklan pada pesan singkat yang terdiri atas bagian isi dan bagian akhir, tanpa bagian awal.

Dari struktur bagian isi, dapat diketahui bahwa bagian ini memaparkan produk yang ditawarkan yang berisi layanan internet tanpa kabel di beberapa lokasi, berita artis, dan nada latar dering. Selanjutnya dipaparkan bagian penutup yang mengikuti bagian isi.

\subsubsection{Bagian Penutup}

Bagian penutup iklan dapat berupa keterangan nomor yang merupakan bagian dari prosedur untuk mendapatkan produk yang ditawarkan, informasi biaya, nomor kontak yang dapat dihubungi untuk mendapatkan informasi produk yang ditawarkan, dan lain-lain. Berikut beberapa contoh bagian penutup.

12. Beli NSP GRATIS Mp3 berhadiah Uang Elektronik Ratusan Ribu Rupiah. Info hub ${ }^{\star} 121^{\star} 616 \#$. Trf Rp 3300/7hr. CS:133/188

13 GRATIS RAIH HADIAH IPAD BUATMU! Cuman $1 \mathrm{rb}$ tiap harinya,bisa GRATIS fesbukan lewat internet sepuasnya satu hari penuh! Hub:

${ }^{\star} 123^{\star} 544^{\star} 14 \#$ skrg juga!

14. PROMO SUPER kuota, hanya dengan Rp35K/3GB/30 hari+Tlp 60 Menit/1 Hari, hub ${ }^{\star} 100^{\star} 368 \#$ sekarang juga! Ayooooo buruan!

Pada data (12) dapat dilihat bahwa bagian akhir iklan berupa nomor kontak yang dapat dihubungi untuk menanyakan informasi pemasangan NSP, yaitu *121*616\# dan informasi tarif pemasangan sebesar $R p$ 3300/7hr (Rp 3300 untuk tujuh hari). NSP merupakan singkatan dari Nada Sambung Pribadi. Nada sambung pribadi adalah pengganti nada sambung standar menjadi nada sambung berupa potongan lagu ataupun suara-suara unik ketika orang menelepon pemilik telepon genggam. Pada data (13) bagian penutup berisi nomor yang dapat dihubungi untuk mendapatkan produk yang ditawarkan, yaitu Hub: *123*544*14\#. Pada data (14) juga pengiklan mengakhiri isi ikelan dengan mencantumkan nomor yang dapat dihubungi (hub *100*368\#) untuk mendapatkan produk yang ditawarkan dan ajakan untuk segera memeroleh produk yang ditawarkan melalui kalimat sekarang juga! Ayooooo buruan!.

Pada umumnya bagian penutup iklan pada pesan singkat berupa angka-angka yang menunjuk nomor operator penyedia yang dapat dihubungi konsumen untuk mendapatkan informasi atau prosedur untuk mendapatkan produk yang ditawarkan, misalnya *100*368\#. Oleh karena itu, biasanya diawali dengan singkatan kata hub atau telp yang menunjukkan secara eksplisit kata hubungi.

\subsection{Aspek Penggunaan Bahasa}

\subsubsection{Pilihan Kata}

54 | Ranah Volume 4 Nomor 1 Juli 2015 
Pilihan kata dalam iklan pada pesan singkat bervariatif. Variasi pilihan kata dikarenakan kata-kata yang digunakan berasal dari bahasa Indonesia, gaul, dan bahasa Inggris sebagaimana terlihat pada beberapa contoh di bawah ini.

(15) Long Weekend ga ada kerjaan? Yuk ketik KEPOJTG200 (potong 200 POIN) kirim ke 777. Dptkn Total Hadiah 5 Voucher Alfamart @Rp1juta.Info http:// goo.gl/TnMshS.S\&K

(16) Valentine gini perlu dong Pulsa Jutaan \& PowerBank! Spesial buat kmu yg suka donlotklip romantic Korea Rp3300/7hr. Buruan hub ${ }^{\star} 123^{\star} 2200^{\star} 1 \#$ CS:817

(17) Met pagi kawan, sekarang kamu bisa dpt GRATIS 1jam seharian hanya dengan nelpon 5Mnt ke smua XL (Rp100/Mnt).

Pada data (15) terdapat pilihan kata bahasa Inggris, yaitu Long Weekend. Long Weekend berarti berarti hari libur di akhir Minggu, yaitu liburan pada hari Sabtu dan Minggu. Pada data (16) terdapat interjeksi dong sebagai penanda ragam informal. Selain itu, terdapat penggunaan bahasa Inggris, yaitu donlot dan romantic. Kata donlot berasal dari kata download yang padanannya dalam bahasa Indonesia adalah unduh dan kata romantic berasal dari bahasa Inggris yang padanannya dalam bahasa Indonesia adalah romantis. Pada data (17) terdapat ucapan salam met pagi dan sapaan kawan dan kamu yang menunjukkan ragam informal. Penggunaan sapaan dan salam ini bertujuan untuk menciptakan keakraban dengan penerima pesan (calon konsumen).

Dari data diketahui bahwa pilihan kata informal nelpon, bisa, gini, dan dong digunakan untuk memperhalus maksud penyampaian iklan sehingga tidak terasa terlalu langsung pada isi pesan iklan. Selain itu, ragam informal menciptakan konteks santai dalam penyampaian pesan iklan sehingga lebih berterima kepada pembaca iklan.

\subsubsection{Kalimat}

Kalimat dalam iklan pada pesan singkat terdiri atas beberapa kalimat tunggal sederhana atau kalimat majemuk. Jumlah kalimat yang digunakan bervariasi asalkan berprinsip pada keefisienan, keefektifan, dan kejelasan penyampaian pesan kepada penerima pesan. Berdasarkan pengamatan jumlah kalimat paling sedikit dua kalimat dan maksimal empat kalimat. Pembatasan jumlah kalimat dilakukan karena jumlah karakter pada pesan singkat terbatas. Sementara itu, aspek penggunaan tanda baca tidak terlalu diperhatikan. Berikut beberapa contoh penggunaan kalimat dalam iklan.

(18) Tlp ke *123*252*2\# buat pake backsound suara macet, romantic, lapangan bola dll pas telponan. Pilih dan bikin temen tlpnan km penasaran. Cuma $9 \mathrm{rb} / 30 \mathrm{hr}$ cyiiin.

(19) Mau pny kenalan dari bandung, Serang, Jakarta, Bogor, Depok, Cianjur, Tasik, Yogya, Pekalongan dll se-Indonesia? Telp *123*248*1\# dan gabung di ZCHAT! 
Data (18) terdiri dari tiga kalimat sederhana dengan beberapa pelesapan. Kalimat dalam iklan ini dapat diuraikan menjadi kalimat lengkap berikut ini.

(18.1) (Kamu) telpon ke *123*252*2\# buat pake backsound suara macet, romantic, lapangan bola dll pas telponan.

(18.2) (Kamu) pilih dan bikin temen telponan kamu penasaran.

(18.3) (Harga telpon) cuma 9rb/30hr cyiiin.

Ketiga kalimat merupakan kalimat aktif. Pada kalimat (18.1) terdapat pelesapan subjek kamu dan verbanya telpon. Kalimat (18.2) merupakan kalimat aktif dengan predikatnya, yaitu pilih dan bikin. Kalimat (18.3) juga merupakan kalimat aktif dengan pelesapan subjek harga telpon. Pelesapan subjek pada kalimat (18.1) dan (18.2) dimaksudkan untuk lebih menekankan dan mengedepankan verba, yaitu telpon, pilih, dan bikin. Pilihan verba telpon, pilih, dan bikin merupakan inti dari pesan iklan, yaitu meminta penerima pesan untuk melakukan apa yang disebutkan pada verba kalimat ini. Pelesapan subjek pada kalimat (18.3) dilakukan karena dianggap apa yang dilesapkan (harga telpon) tidak terlalu penting bagi penerima pesan. Pelesapan subjek mungkin juga dilakukan karena penerima pesan dianggap sudah mengetahui bahwa subjek pada kalimat tersebut adalah harga telpon sehingga demi keefesienan tidak perlu dicantumkan.

Pada data (19) terdapat dua kalimat sederhana dengan beberapa pelesapan. Kalimat dalam iklan ini dapat diuraikan menjadi kalimat lengkap berikut ini.

(19.1) (Kamu) Mau pny kenalan dari bandung, Serang, Jakarta, Bogor, Depok,

Cianjur, Tasik, Yogya, Pekalongan dll se-Indonesia?

(19.2) (Kamu) telp *123*248*1\# dan gabung di ZCHAT!

Kedua kalimat merupakan kalimat aktif. Pada kalimat (19.1) terdapat pelesapan subjek kamu dan verbanya mau punya. Kalimat (19.2) juga merupakan kalimat aktif dengan pelesapan subjek kamu. Kalimat (19.2) merupakan kalimat majemuk setara yang terdiri atas dua kalimat, yaitu (kamu) telp *123*248*1\# dan (kamu) gabung di ZCHAT. Pelesapan subjek pada kalimat (19.1) dan (19.2) dimaksudkan untuk lebih menekankan dan mengedepankan verba, yaitu mau punya, telpon, dan gabung. Pilihan verba mau punya, telpon, dan gabung merupakan inti dari pesan iklan, yaitu meminta penerima pesan untuk melakukan apa yang disebutkan pada verba kalimat ini.

Data (20) merupakan penawaran RBT atau nada latar dering merupakan pilihan suara-suara unik ketika orang menelepon pemilik telepon genggam. Pada data (20) terdapat dua kalimat kalimat sederhana dengan beberapa pelesapan. Kalimat dalam iklan ini dapat diuraikan menjadi kalimat lengkap berikut ini

(20.1) (Kamu) CEK *123*94*5\# unt Aktifkan BONUS NELPON 15mnt + RBT:

"HALO, DGN SIAPA? UDAH JANJI BELUM? TADI SIAPA

56 | Ranah Volume 4 Nomor 1 Juli 2015 
NAMANYA? GA ADA NEH DI DAFTAR UNT TERIMA TELPON HR

$I N I^{\prime \prime}$

(20.2) (Harga aktivisasi bonus) Rp4rb /bln

Kedua kalimat merupakan kalimat aktif. Pada kalimat (20.1) terdapat pelesapan subjek kamu dan verbanya cek. Selain itu, terdapat pemerian RBT, yaitu HALO, DGN SIAPA? UDAH JANJI BELUM? TADI SIAPA NAMANYA? GA ADA NEH DI DAFTAR UNT TERIMA TELPON HR INI. Kalimat (20.2) juga merupakan kalimat aktif dengan pelesapan subjek harga aktivisasi bonus. Pelesapan subjek terjadi karena penerima pesan dianggap sudah memahami bahwa harga yang tercantum merupakan biaya yang dikenakan untuk mendapatkan pilihan RBT ini.Dari pembahasan segi kalimat pada iklan, dapat diketahui bahwa satu wacana iklan pada pesan singkat biasanya terdiri atas dua baris atau tiga kalimat. Kalimat-kalimat itu dapat berupa kalimat tunggal atau kalimat majemuk. Pada umumnya kalimat tunggal yang ditemukan berupa kalimat verbal, yaitu kalimat yang predikatnya verba karena inti dari iklan adalah penawaran kepada penerima pesan untuk melakukan tindakan pembelian dengan mengikuti beberapa langkah seperti telpon, cek, hubungi, beli, dapatkan dan lain-lain.

\subsubsection{Penulisan Ejaan}

Dalam buku pedoman penulisan ejaan dalam Bahasa Indonesia disebutkan ada beberapa hal yang perlu dicermati, yaitu mengenai pemakaian huruf (pemakaian huruf kapital, pemakaian huruf miring), penulisan kata (gabungan kata, penulisan bentuk ulang, penulisan kata depan, penulisan singkatan dan akronim), penggunaan tanda baca (tanda titik, tanda koma, dan sebagainya). Dalam kajian wacana iklan dalam pesan singkat ini hanya dipaparkan penulisan huruf kapital dan singkatan yang digunakan dalam wacana iklan ini. Perhatikan contoh penggunaan ejaan pada iklan baris berikut ini.

\subsubsection{Pemakaian Huruf Kapital}

Berdasarkan kaidah EYD huruf kapital digunakan untuk menulis nama diri, gelar, judul, dan sebagainya. Namun, penulisan huruf kapital dalam iklan pada pesan singkat dilakukan untuk mementingkan bagian informasi tertentu seperti tampak pada beberapa contoh berikut ini.

SELAMAT GRATIS TELP + VOUCHER BELANJA RP 1 JUTA + SIKAT PULSA 100.000+RBT SINETRON MAHABRATA Cek ${ }^{\star} 123{ }^{*} 355^{\star} 3$ \# utk aktifin Gratisan Telpon + RBT.cm 3300/mg GLO36B2

(22) GRATIS RAIH HADIAH IPAD BUATMU! Cuman 1 rb tiap harinya, bisa GRATIS fesbukan lewat internet sepuasnya satu hari penuh! Hub: ${ }^{*} 123 * 544^{\star} 14 \#$ juga!

Pada data (21) penggunaan huruf kapital terdapat pada bagian pendahuluan wacana iklan, yaitu SELAMAT GRATIS TELP+ VOUCHER BELANJA RP 1 JUTA + SIKAT PULSA 100.000+RBT SINETRON MAHABRATA. Penggunaan huruf kapital ini dimaksudkan untuk mementingkan informasi dan menarik perhatian pembaca pesan 
terhadap produk yang ditawarkan. Pada data (22) penggunaan huruf kapital terdapat pada bagian pembuka, yaitu GRATIS RAIH HADIAH IPAD BUATMU!. Penggunaan huruf kapital untuk menarik perhatian pembaca dan tawaran hadiah. Selanjutnya, penggunaan huruf kapital terdapat pada penulisan kata GRATIS pada kalimat Cuman 1 rb tiap harinya,bisa GRATIS fesbukan lewat internet sepuasnya satu hari penuh! Hub: *123*544*14\# juga!. Penulisan kata gratis dengan huruf kapital bertujuan untuk menekankan kesan dan menarik pembaca bahwa tawaran penawaran produk ini tidak berbayar.

Dari kedua data tersebut dapat disimpulkan bahwa penggunaan huruf kapital difungsikan untuk menarik perhatian pembaca pesan sehingga akan lebih memperhatikan isi pesan yang berbeda ukurannya. Huruf kapital juga dapat digunakan untuk mementingkan informasi yang dianggap penting untuk diketahui pembaca pesan dibandingkan informasi lainnya.

\subsubsection{Penulisan Singkatan}

Berdasarkan KBBI (Kamus Besar Bahasa Indoensia) singkatan adalah hasil menyingkat (memendekkan), berupa huruf atau gabungan huruf, misalnya DPR, KKN, yth., dsb., dan hlm.). Singkatan digunakan untuk memadatkan pesan karena keterbatasan jumlah karakter yang digunakan pada pesan singkat. Berikut beberapa contoh penggunaan singkatan dalam iklan pada pesan singkat.

\section{Tabel 2}

\section{Singkatan dalam Iklan pada Pesan Singkat}

\section{No. Contoh Iklan}

(23) AKU MAH APA ATUH.Kaya iklan aja br Muncul lgsg di skip.Ayo Tunjukin Bakat nyanyi lo brg Cita Citata.Ktk *123*89*1\# atau Tlp 1602.Ada hadiah ttl JUTAAN.CS:817

(24) Punya pngalaman menyeramkan? Ban dingin dg crita yg ini.ketik*123*234\# atau Tlp23401 lalu tekan 30 utk HOROR, hny Rp1500/30mnt/7hari.Ingat jgn prnah dgr SENDIRIAN

(25) NELPON MURAH! 3 jam Telp ssm Tsel 00:00 s/d 23:59, HANYA Rp.500. Ketik YA krm ke 5115.Promo sd tgl 27Mei15. Pastikan pulsa ckp *888\#, hanya $1 X$ transaksi

\section{Singkatan}

baru $\rightarrow$ br; langsung $\rightarrow$ lgsl; bareng $\rightarrow$ brg; ketik $\rightarrow$ ktk; telpon $\rightarrow$ tlp; total $\rightarrow$ ttl; $\mathrm{CS} \rightarrow$ Customer Service

pengalaman $\rightarrow$ pngalaman; ban $\rightarrow$ badan; dg $\rightarrow$ dengar; cerita $\rightarrow$ crita; yang $\rightarrow$ yg; telpon $\rightarrow$ tlp; untuk $\rightarrow$ utk; hanya $\rightarrow$ hny; menit $\rightarrow$ mnt; jangan $\rightarrow$ jgn; pernah $\rightarrow$ prnah; dengar $\rightarrow$ dgr

telpon $\rightarrow$ telp ; sesama $\rightarrow$ ssm; Telkomsel $\rightarrow$ Tsel; sampai dengan $\rightarrow$ s/d; kirim $\rightarrow$ krm; sd $\rightarrow$ sampai dengan; tanggal $\rightarrow$ tgl; cukup $\rightarrow$ ckp

Jika melihat bentuk penulisan singkatan pada contoh di atas tampak bahwa singkatan ditulis secara bebas menurut kehendak penulis iklan dan tidak ada aturan baku. Pada beberapa singkatan terlihat tidak konsisten, misalnya pada data (24) terdapat singkatan $d g$ dan dgr yang mengacu pada kata dengar dan pada data (25) 
terdapat singkatan $s / d$ dan $s d$ yang mengacu pada kata sampai dengan.

Namun, ketidakkonsistenan dan kebebasan menggunakan singkatan tidak mengakibatkan kesulitan dalam memahami isi iklan karena penyingkatan yang digunakan disesuikan dengan konteks isi iklan. Dalam konteks isi iklan pada data (24) terdapat singkatan dgn tidak diartikan sebagai singkatan dari kata dengan karena konteks isi iklan adalah penawaran cerita berisi pengalaman menyeramkan atau horor. Oleh karena itu, dgn merupakan singkatan yang mengacu pada kata dengar.

\subsection{Aspek Pragmatik}

Iklan dalam pesan singkat terdiri dari beberapa tindak tutur. Tindak tutur dalam iklan pada pesan singkat dimaksudkan untuk memengaruhi pembaca pesan supaya melakukan tindakan pembelian terhadap produk yang ditawarkan. Berikut beberapa contoh tindak tutur dalam iklan.

(26) Selamat!Anda bisa membeli PAKET 500 selama 3 hari sd. 12-06-2015 23:59:59. Pilih paket di ${ }^{\star} 100{ }^{\star} 999 \#$. Ayo perbanyak beli PAKET 500!

(27) Beli saldo bermain 30ribu GRATIS extra tambahan 15ribu hanya di TIMEZONE, Tukarkan SMS ini segera!!

(28) WOW!!! Isi pulsa s/d Rp50rb,dptkan Total Pulsa Rp60rb(10rb pulsa Tsel utk 3hr).Promo s/d 3Mar15. Cek bonus di*889\#.Se Kberlaku

Pada data (26) terdapat tuturan ekspresif dan direktif. Tuturan ekspresif dinyatakan dengan kata Selamat!. Tuturan ini dimaksudkan untuk menarik perhatian pembaca pesan sekaligus memberikan kesan bahwa pembeli paket ini telah memperoleh keberuntungan dengan membeli produk yang ditawarkan pemasang iklan. Tuturan direktif terdapat pada kalimat Pilih paket di*100*999\# dan Ayo perbanyak beli PAKET 500!. Tuturan ini dimaksudkan untuk memberikan petunjuk dan arahan kepada pembaca pesan yang berminat untuk mengikuti cara memeroleh produk sekaligus mengajak pembaca untuk membeli produk ini. Pada data (27) terdapat tuturan direktif, yaitu Beli saldo bermain 30ribu GRATIS extra tambahan 15ribu hanya di TIMEZONE, Tukarkan SMS ini segera!!. Tuturan ini berupaya untuk memengaruhi pembaca pesan sehingga pembaca pesan dapat melakukan pembelian saldo untuk bermain permainan di TIMEZONE.

Pada data (28) terdapat tuturan ekspresif, yaitu WOW!!!. Tuturan ini menunjukkan kekaguman atau pujian terhadap produk yang ditawarkan. Selanjutnya, tuturan direktif digunakan dalam data ini adalah Isi pulsa s/d Rp50rb, dptkan Total Pulsa Rp60rb(10rb pulsa Tsel utk 3hr) dan Cek bonus di*889\#. Tuturan direktif ini digunakan untuk memengaruhi pembaca pesan agar mengikuti petunjuk yang diberikan ketika akan membeli produk yang ditawarkan.

\section{Simpulan}

Berdasarkan kajian wacana iklan pada pesan singkat dapat disimpulkan bahwa struktur wacana, penggunaan bahasa, dan aspek pragmatik memiliki beberapa ciri. Struktur wacana iklan pada pesan singkat terdiri atas bagian pembuka, isi, dan penutup.

Pada aspek penggunaan bahasa menunjukkan bahwa kalimat tunggal maupun 
kalimat majemuk digunakan dengan beberapa pelesapan. Pelesapan dilakukan dengan anggapan bahwa bagian yang dilesapkan sudah dapat dipahami pembaca pesan tanpa mengurangi isi informasi yang disampaikan. Penulisan dengan huruf kapital kerap dilakukan untuk menunjukkan dan menekankan bagian informasi tertentu yang dianggap penting serta untuk menarik pembaca dengan variasi huruf besar dan kecil.

Dari segi pragmatik, tuturan yang terdapat pada iklan menunjukkan jenis tindak tutur direktif yang dipadukan dengan tuturan ekspresif. Tuturan direktif dimaksudkan untuk memengaruhi pembaca agar melakukan tindakan yang diharapkan pembuat iklan, misalnya beli, cek, pilih, dll. Tuturan ekspresif dimaksudkan untuk menyanjung produk itu sendiri atau ucapan selamat kepada calon pembeli yang dianggap akan membeli produk, misalnya selamat, khusus untuk Anda, dsb.

Temuan lain menunjukkan bahwa isi iklan pada pesan singkat memiliki ciri khas. Pertama, iklan disampaikan secara personal tidak seperti iklan pada media lain yang ditujukan kepada pembaca secara luas. Iklan diterima calon konsumen melalui telepon gengam pribadi. Kedua, pesan iklan disampaikan dengan diikuti prosedur untuk memiliki produk, misalnya telpon $* 889 \#$. Setelah prosedur diikuti, produk yang dipesan dapat langsung diterima tanpa menunggu lama. Isi iklan biasanya menyangkut gaya hidup, misalnya nada dering pribadi, berita gosip selebriti, ajakan bergabung ke komunitas untuk mengobrol, berita seputar bintang sepakbola, dan sebagainya.

\section{Daftar Pustaka}

Baryadi, I Praptomo. 2002. Dasar-Dasar Analisis Wacana dalam Ilmu Bahasa. Yogyakarta: Pustaka Gondho Suli.

Basu Swastha, D. H. 1994. Asas-Asas Marketing. Yogyakarta: Liberty.

Kasali, Rhenald. 1992. Manajemen Periklanan Konsep dan Aplikasinya di Indonesia. Jakarta: Pustaka Utama Grafiti.

Keraf, G. 1995. Komposisi. Ende: Nusa Indah.

Kridalaksana, H. 2001. Kamus Linguistik. Jakarta: Gramedia Pustaka.

Leech, Geoffrey.1993. Prinsip-Prinsip Pragmatik (Diterjemahkan oleh Oka). Jakarta: Universitas Indonesia Press.

Mulyana. 2005. Kajian Wacana: Teori, Metode \& Aplikasi Prinsip-Prinsip Analisis Wacana. Yogyakarta: Tiara Wacana.

Pusat Pembinaan dan Pengembangan Bahasa. 1997. Pedoman Umum Ejaan yang Disempurnakan. Jakarta.

Rahardi, Kunjana. 2003. Berkenalan dengan Ilmu Bahasa Pragmatik. Malang: Dioma.

Rani, Abdul dan Arifin Bustanul. 2000. Prinsip-Prinsip Analisis Wacana. Jakarta: Departemen Pendidikan Nasional.

Searle. 1969. Speech Acts An Essay in The Philosophy of Language. Oxford: Basil Blacwell.

Sudaryanto. 2001. Metode dan Aneka Teknik Analisis Bahasa: Pengantar Penelitian Wahana Kebudayaan secara Linguistis. Yogyakarta: Duta Wacana University Press.

Tim Redaksi. 2008. Kamus Besar Bahasa Indonesia. Edisi Keempat. Jakarta: Gramedia Pustaka Utama.

Wijana, Dewa Putu. 1996. Dasar-Dasar Pragmatik. Yogyakarta: Andi.

Wijana, Dewa Putu. 2009. Analisis Wacana Pragmatik: Kajian Teori dan Analisis. Surakarta: Yuma Pustaka.

60 | Ranah Volume 4 Nomor 1 Juli 2015 